\section{Long-term Complications from Breast Augmentation by Injected Polyacrylamide Hydrogel}

Eon Rok Do, Jeong Su Shim

Department of Plastic and Reconstructive Surgery, Catholic University of Daegu School of Medicine, Daegu, Korea

\section{Correspondence: Jeong Su Shim}

Department of Plastic and Reconstructive Surgery, Catholic University of Daegu College of Medicine, 33 Duryugongwon-ro 17-gil, Nam-gu, Daegu 705-718, Korea

Tel: +82-53-650-4578, Fax: +82-53-650-4584

E-mail: jsshim@cu.ac.kr

No potential conflict of interest relevant to this article was reported.

Received: 17 Dec 2011 • Revised: 12 Apr 2012 • Accepted: 13 Apr 2012 pISSN: 2234-6163・ elSSN: 2234-6171

http://dx.doi.org/10.5999/aps.2012.39.3.267 • Arch Plast Surg 2012;39:267-269

Copyright (C) 2012 The Korean Society of Plastic and Reconstructive Surgeons This is an Open Access article distributed under the terms of the Creative Commons Attribution Non-Commercial License (http://creativecommons.org/licenses/by-nc/3.0/) which permits unrestricted non-commercial use, distribution, and reproduction in any medium, provided the original work is properly cited.

Currently, the most commonly used injection fillers are broadly classified into hyaluronic acid-based absorbable fillers and semi-permanent fillers. Polyacrylamide hydrogel (PAAG) is classified as a semipermanent filler and is manufactured under diverse brands including Aquamid, Bio-alcamid, Interfall, Outline, Formacryl, Bioformacryl, Argiform, and Amagingel.

The authors experienced a case of a thirty-fouryears-old female patient who underwent PAAG injection for breast augmentation and developed complications ten years after the injection. A number of articles have reported complications of PAAG injection for aesthetic purposes, but it was difficult to find any Korean reports on complications that have occurred as long as ten years after breast augmentation with PAAG.

The patient presented with breast lumps, which had developed six months earlier. The lumps were palpable in two locations: at the upper outer part of the right breast and at the center of the chest between the breasts. The patient had undergone filler injection for breast augmentation ten years earlier at a local clinic in Shenyang, China. The patient only remembered a filler material called Amazingel was used, but did not recall the quantity of the material injected. Through a tracing investigation, we determined that Amazingel was a PAAG-type of filler material manufactured in China. During physical examination, symptoms such as tenderness and a burning sensation were not observed around the lumps, and there was no discomfort other than contour abnormalities resulting from the lumps. A preoperative magnetic resonance imaging (MRI) scan revealed fluid-filled sacs in the retroglandular areas of both breasts, and part of the contents appeared to have leaked out of the capsules (Fig. 1). The MRI images showed filler material with a low signal on $\mathrm{T} 1$ weighted images and a high signal on T2 weighted images. PAAG consists of a large quantity of water and has a tendency to appear dark in $\mathrm{T} 1$ weighted images and bright in $\mathrm{T} 2$ weighted images [1].

The author performed breast implant removal surgery under general anesthesia. Two stab incisions were made in the inframammary folds of the breasts, and dissections were made below the mammary glands. A yellow, granular jelly-like substance was drawn out by breaking off the fibrous capsules (Fig. 2). The foreign substance was extirpated as much as possible by can-

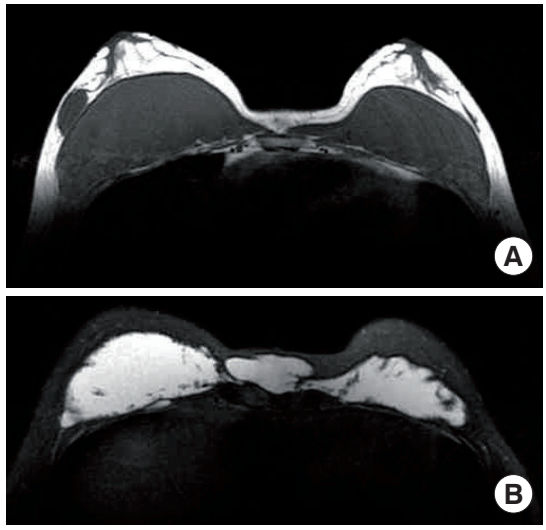

Fig. 1.

Axial magnetic resonance images show polyacrylamide hydrogel as a low signal on $\mathrm{T} 1$ weighted images (A) and as a high signal on $\mathrm{T} 2$ weighted images (B) in the retroglandular spaces of the breasts. The images show nodular lesions in the upper outer quadrant of the right breast and intermammary area. 
Fig. 2.

(A) Preoperative view of polyacrylamide hydrogel (PAAG)induced lumps in the upper, outer quadrant of the right breast and intermammary area. (B) The injected PAAG shows a yellow, granular, jelly-like appearance.
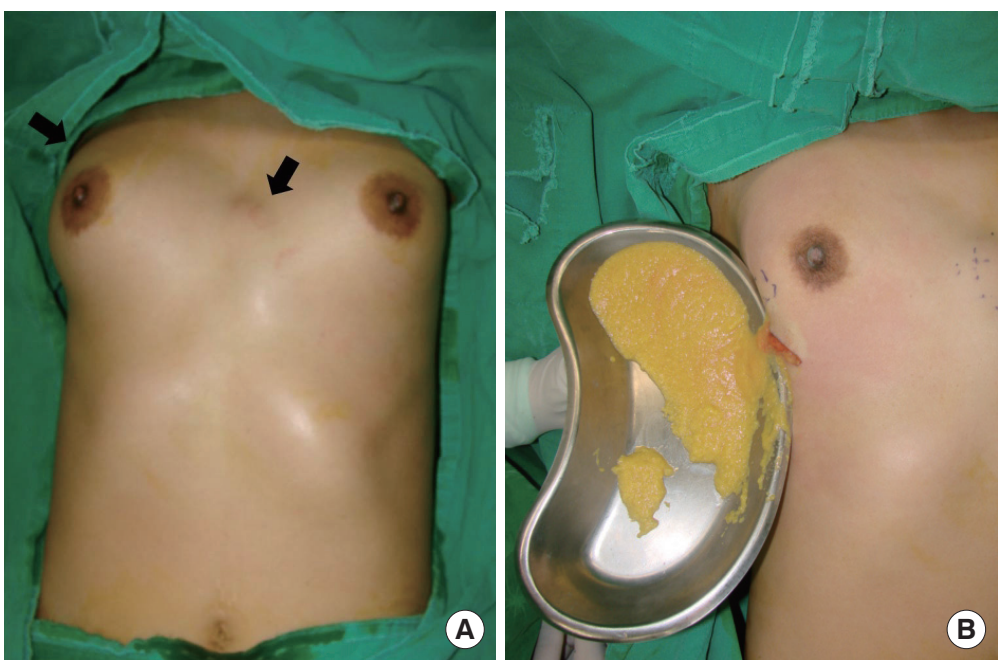

Fig. 3.

(A) Microscopic findings show atypical dark violet material $\left(H \& E_{1} \times 40\right)$ and $(B)$ a homogenously built polymer gel pool $\left(H \& E_{1} \times 200\right)$.
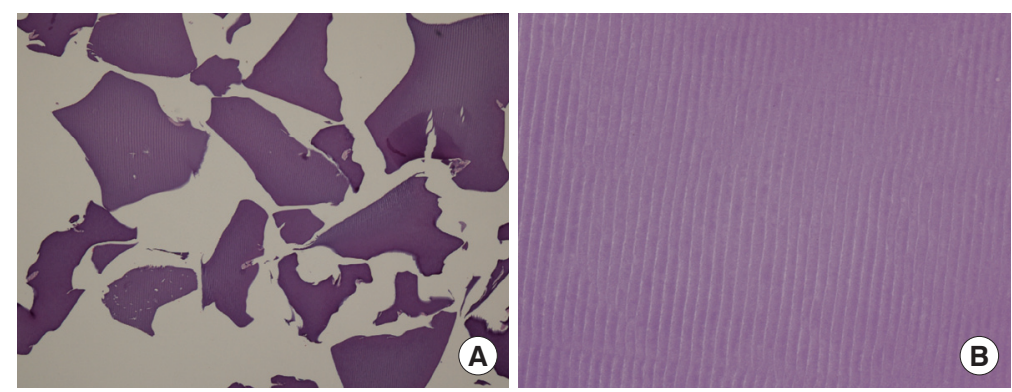

nula suction and by applying pressure to the breasts. The surrounding tissues as well as the space emptied of the filler were irrigated a number of times with saline solution.

The T2 weighted image of the pre-operational MRI scan revealed that the gel had a bright signal similar to that of water and presented a lobular outline as well as a zebra-stripe appearance with many septa in it. These have been found to be the characteristics of PAAG in MRI findings in previous studies on polyacrylamide hydrogels [1]. The gross findings of the gel removed from the patient's body resembled those that have been found in PAAG removal cases in previous studies $[1,2]$. The breast filler was stained with hematoxylin and eosin (H\&E), and we observed homogeneous, atypical, violet substances under a microscope. These characteristics were identical to those found in microscopic findings in the studies of Zhao and Cristesen [1-3] (Fig. 3).

PAAG is a transparent jelly-type material and consists of $2.5 \%$ cross-linked polyacrylamide and $97.5 \%$ non-pyrogenic water. It is thought that PAAG is a nontoxic, non-allergenic synthetic biomaterial and is relatively safe for implants due to its hydrophilic and non-degradable characteristics [4]. PAAG was first introduced for aesthetic purposes in the Ukraine in the 1980s and was widely utilized in the old Soviet Union and Eastern Europe. In 1997, PAAG was approved by the Chinese Food and Drug Administration and it has been a popular injection option for local hospitals and private cosmetic clinics in China for correcting facial depressions, lip enhancement, and breast augmentation [4]. However, the safety and benefits of PAAG have also been controversial in China, and as the number of reports on late complications of PAAG have increased, it now rarely used in university hospitals.

Many complications from PAAG injections for aesthetic purposes have been reported thus far $[4,5]$ including breast induration, lump formation, hematoma, inflammation, infection, mastalgia, and lactation. Among these complications, breast induration or lump formation are the most common complications, especially in patients with insufficient breast subcutaneous tissues $[1,4,5]$. In most cases, removal of PAAG from the breasts led to immediate improvement of the symptoms.

In this case, it was difficult for the authors to remove the gel completely, even with cannula suction, saline irrigation, and manual physical pressure on the 
breasts. The PAAG was spread over the breast tissues and some even reached deep into the pectoralis major muscle. Qaio et al. [5] reported that patients still had residual PAAG in breast tissues after blind suction, and that repeated blind suctions could injure the surrounding normal breast tissues. Therefore, it is helpful to perform an open surgery through periareolar and inframammary incisions for effective removal, and it is necessary to mention the possibility of incomplete removal to patients prior to the surgery.

The MRI scan was helpful for revealing and treating the complication in this case. PAAG can be easily distinguished on an MRI image from the signals of mammary glands, fat tissue, and muscles. An MRI scan is useful in demonstrating the distribution of injected PAAG and associated lesions as well as planning the treatment for complications of PAAG injection.

According to other reports on similar cases [2], patho-histological examinations have revealed macrophages, giant cells, and lymphocytes in the tissues surrounding the injected PAAG, with foreign body reaction findings. This indicates that the PAAG in breasts affects surrounding tissues and may cause serious foreign body reactions. However, our case report has its limitations in that it does not include a pathological report about the surrounding tissues.

Nonetheless, the remarkable thing about this case is that the patient visited the hospital ten years after the PAAG injection with only the appearance of breast lumps and without any other symptoms such as tenderness, induration, or changes in appearance. Under circumstances where various injection fillers for aesthetic purposes are widely used clinically, this case is clinically remarkable.

\section{References}

1. Xu LY, Kong XQ, Tian ZX, et al. Magnetic resonance imaging on complications of breast augmentation with injected hydrophilic polyacrylamide gel. Chin Med J (Engl) 2006;119:1311-4.

2. Christensen LH, Breiting VB, Aasted A, et al. Long-term effects of polyacrylamide hydrogel on human breast tissue. Plast Reconstr Surg 2003;111:1883-90.

3. Zhao Y, Qiao Q, Yue Y, et al. Clinical and histologic evaluation of a new injectable implant: hydrophilic polyacrylamide gel. Ann Plast Surg 2004;53:267-72.

4. Chao MJ, Yin WM. Application of hydrophilic polyacrylamide gel in augmentation mammaplasty. J Pract Aesth Plast Surg 2000;11:16-8.

5. Qiao Q, Wang X, Sun J, et al. Management for postoperative complications of breast augmentation by injected polyacrylamide hydrogel. Aesthetic Plast Surg 2005;29:156-61. 